\title{
Three sporadic cases of Creutzfeldt-Jakob disease in China and their clinical analysis
}

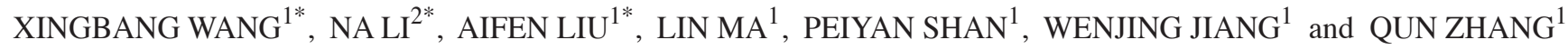 \\ ${ }^{1}$ Department of Neurology, Cadre Clinic, Qilu Hospital of Shandong University, Jinan, Shandong 250012; \\ ${ }^{2}$ Department of Dermatology, The Affiliated Hospital of Shandong University of \\ Traditional Chinese Medicine, Jinan, Shandong 250011, P.R. China
}

Received December 17, 2015; Accepted January 6, 2017

DOI: $10.3892 / \mathrm{etm} .2017 .4832$

\begin{abstract}
The present study described the characteristics of three cases of Creutzfeldt-Jakob disease (CJD) in China and analyzed their clinical presentations. The clinical information of the three cases was collected and analyzed. Blood and cerebrospinal fluid (CSF) specimens of the patients were collected for detection of the prion protein (PRNP) gene and 14-3-3 protein levels. Dynamic changes of electroencephalograms (EEGs) and brain magnetic resonance images (MRIs) were also observed. All the three cases were sporadic CJD cases. They presented with symptoms including hyposthenia, progressive memory loss, truncal and limb ataxia, dysarthria, lowered vision acuity, bucking, language disorders, myoclonia and akinetic mutism state. One of the three cases was associated with a prolonged duration of $>6$ years. The EEG of two cases showed slow biphasic waves. The diffusion-weighted MRI sequence revealed abnormal hyperintensity and bilateral ribboning in the cortex. Two patients tested positive for the 14-3-3 protein in the CSF. All patients were of methionine homozygosity at codon 129 in the gene encoding PRNP protein and one patient had a mutation. The CJD cases showed differences in terms of symptoms and disease duration. Subacute onset was common and with attentive nursing and supportive treatments, one of the patients had a prolonged survival time of $>6$ years.
\end{abstract}

Correspondence to: Dr Lin Ma, Department of Neurology, Cadre Clinic, Qilu Hospital of Shandong University, 107 Wenhua Xi Road, Jinan, Shandong 250012, P.R. China

E-mail:20893792@qq.com

*Contributed equally

Key words: Creutzfeldt-Jakob disease, clinical diagnosis, duration, clinical analysis, sporadic

\section{Introduction}

Creutzfeldt-Jakob disease (CJD) is a progressive neurodegenerative disorder that is caused by prion protein deposition in the central nervous system. As the most common type of human transmissible spongiform encephalopathy, CJD is incurable and fatal with a duration from a few months to two years (1). Typical CJD triad symptoms include progressive dementia, myoclonus and electroencephalographic (EEG) changes (periodic triphasic sharp wave complexes) (2). Traditionally, CJD is classified as sporadic (sCJD), familial (fCJD), iatrogenic (iCJD) and variant CJD (vCJD) (3). Different subtypes are associated with specific clinical symptoms and pathological features $(4,5)$. sCJD, accounting for $\sim 85 \%$ of all cases worldwide, is categorized into six subtypes according to the methionine $(\mathrm{M})$ /valine $(\mathrm{V})$ polymorphism at codon 129 of the PRNP gene $(6,7)$. fCJD accounts for $5-10 \%$ of all cases and is an autosomal dominant disorder associated with various mutations of the PRNP gene $(8,9)$. The main causes of iCJD include contaminated human hormone supplements, corneal transplantation and transplantation of cadaveric dura mater (10). At present, vCJD, which is transmitted from cows with bovine spongiform encephalopathy to humans, mainly affects younger adults in Europe with different clinical, etiological and neuropathological features as well as risk factors compared with other types of CJD (11-13).

Although final diagnosis of CJD requires neuropathological biopsy examination of affected brain tissues, nonpathological methods are currently used worldwide for the early diagnosis and prevention of CJD (14). At present, the diagnosis of CJD is frequently delayed or CJD remains unidentified; therefore, physicians require enhanced knowledge and awareness to better recognize CJD. Accordingly, the aim of the present study was to address the clinical characteristics of atypical CJD in China.

\section{Case report}

Subjects. Three cases of CJD were identified between 2005 and 2011 at the Department of Neurology of Cadre Clinic (Qilu Hospital of Shandong University, Jinan, China). In the present study, these 3 cases were re-evaluated according to the World Health Organization (WHO) diagnostic 
criteria (15), and all cases were diagnosed as probable sCJD. The EEG, 14-3-3 protein in the cerebrospinal fluid (CSF), brain MRI images and PRNP gene analysis were obtained from the clinical records of each case. Each of the patients was followed up until death with laboratory analyses and physical examinations. Prior written informed consent regarding presentation of patient data and images was obtained from each patient's relatives and the study was approved by the Ethics Review Board of Qilu Hospital of Shandong University (Jinan, China).

First case. The first case was a 66-year-old man, with no remarkable family or past clinical history. He was admitted to the Department of Neurology in March 2006 with complaints of months of depression and insomnia. The patient had been appearing apathetic, excessively self-aware and anxious to his spouse since September 2005 when he retired, and the symptoms aggravated progressively. In early 2006, the patient presented with insomnia, depression, hypologia, restlessness and decreased short-term memory. The MRI was normal. Mood-stabilizing drugs and psychological counseling showed no improvements.

From July 2006 to January 2007, the patient increasingly presented with mutism as well as with hypologia, somnolence, no interest in the outside world, weakness of the left lower extremity, unsteady gait, clumsiness in movement, visual disturbances, slurred speech, bucking, dullness and further decline in memory. Physical examination showed mild hyposthenia of the left leg, nystagmus, dysarthria, apathy and mild cognitive impairment. All laboratory tests were normal, including routine blood, urine and stool tests, erythrosedimentation, liver and kidney function, thyroid function, antithyroid peroxidase antibodies, antithyroid-globulin antibodies, blood glucose, lipid, folic acid and vitamin B12 levels, autoimmune antibody levels, and screening tests for human immunodeficiency virus and venereal diseases were negative. MRI was conducted at various time-points (Fig.1). In November 2006, MRI showed bilateral subcortical focal ischemic lesions and brain atrophy, the latter of which progressed rapidly since then (Fig. 1A). EEG showed slow waves of background activity without any periodic sharp wave complexes (PSWC). As ischemic infarction could not be ruled out the patient received antiplatelet drugs, selective serotonin reuptake inhibitor antidepressants and cholinesterase inhibitors; however, none of the symptoms improved.

Instead, clinical symptoms markedly deteriorated over the following two months, which led to ataxia of trunk and limbs, aggravating of dysarthria and bucking, and gradual weakened acuity of vision. In February 2007, spontaneous jerky movements of eyes began and then extended to facial muscles within one month. In May, the patient developed involuntary clonus of the left upper limb and lost consciousness two months later. Subsequently, a preliminary diagnosis of CJD was made and the patient received all supporting treatments available, which, however, did not lead to any improvements. The patient then was transferred to other hospitals for treatments of improving cerebrocirculation and cerebrometabolism, but no improvement was shown.

Upon readmission to our hospital, two years after the onset of the disease, the patient's symptoms progressed to akinetic
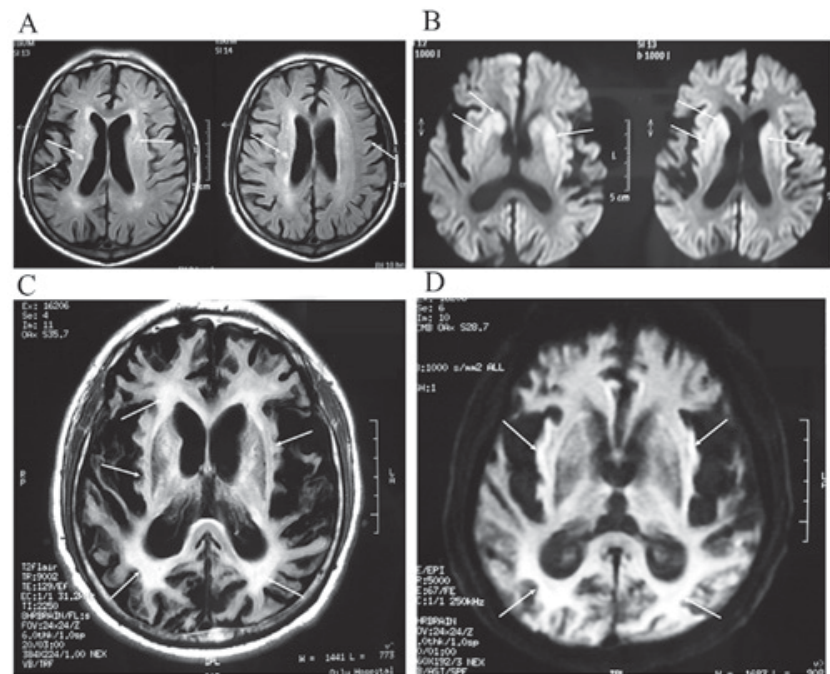

Figure 1. Brain magnetic resonance images of the first case at different time-points. (A) November 2006: Focal ischemic lesions in bilateral subcortical and brain atrophy appeared on FLAIR sequence (arrows); (B) October 2007: Abnormal signal hyperintensity in caudate head and putamen on DWI sequence and the atrophic area was slightly extended (arrows); (C) March 2008: Ventricles surrounding white matter show abnormal signals on FLAIR sequence and atrophy was more evident compared to previous images (arrows); (D) March 2008: Abnormal signal in posterior horn of lateral ventricle and cortical ribboning of insular lobes on DWI sequence (arrows). FLAIR, fluid-attenuated inversion recovery; DWI, diffusion-weighted imaging.

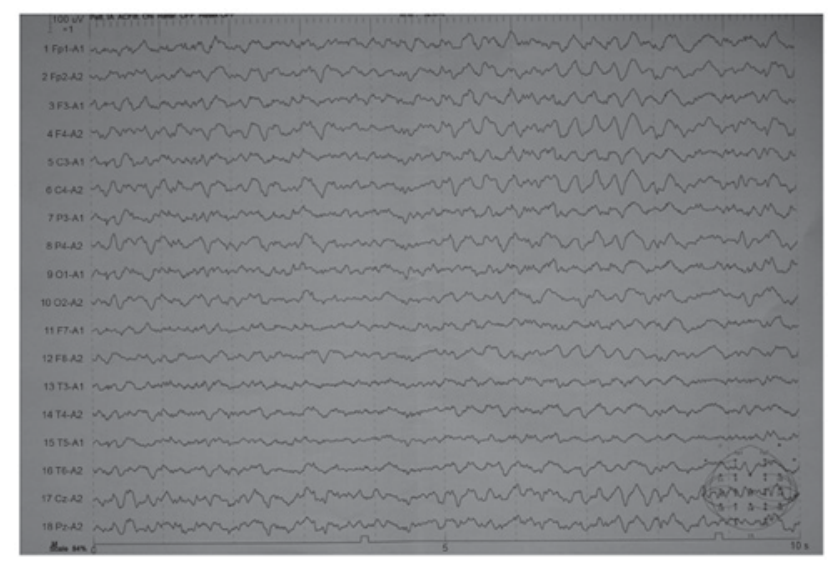

Figure 2. Electroencephalogram of the first case showing considerably slow biphasic waves.

mutism. Neurological examination showed hypermyotonia of four limbs, swallowing disturbances, urinary incontinence and spontaneous myoclonus of the whole body. EEG showed considerable slow biphasic waves just before readmission to our hospital (Fig. 2). Gene analysis revealed that the patient was homozygous for M at codon 129 of the PRNP gene with no mutation. Brain MRI showed bilateral high signal in the caudate and putamen (Fig. 1B). Other physical and laboratory examinations showed no abnormal signs, including negative 14-3-3 protein in the CSF. Subsequent serial MRIs showed significant brain atrophy (Fig. 1C and D).

During the following days, the patient remained in a vegetative state, with myoclonus all day and a persistent lung infection. He was sustained by nasogastric feeding, tracheotomy and cystostomy care. When he reached the akinetic 
A

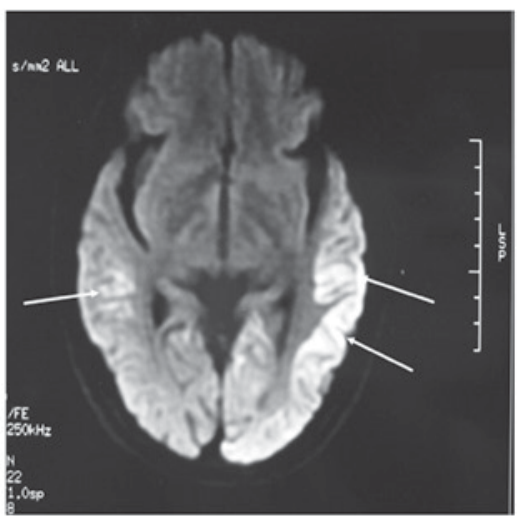

$\mathrm{C}$

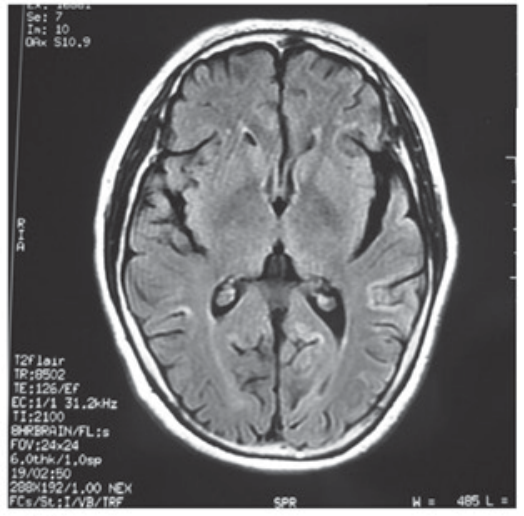

E

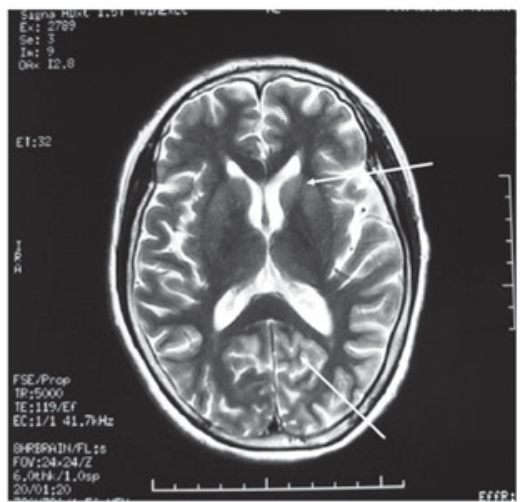

B

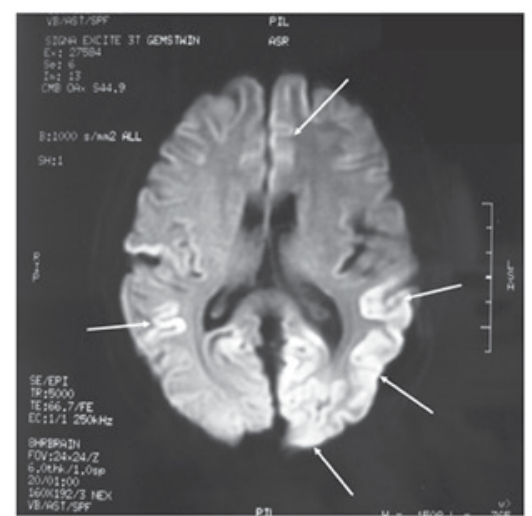

D

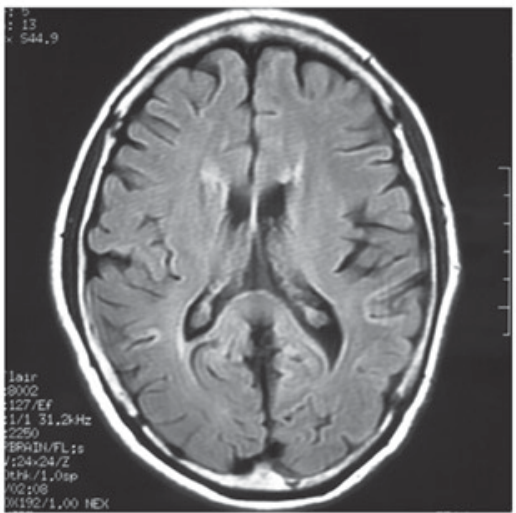

$\mathrm{F}$

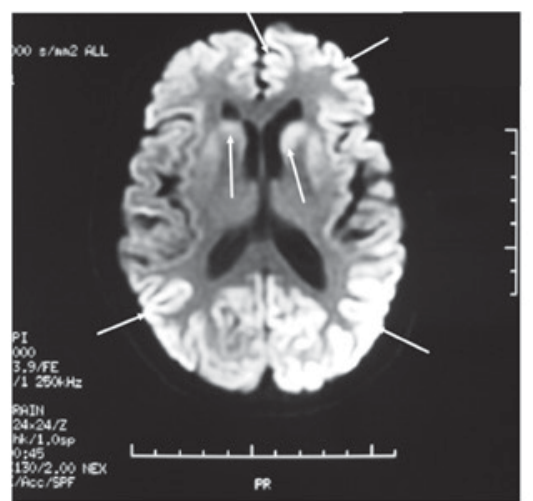

Figure 3. Brain magnetic resonance images of the second case. (A and B) Multiple axial images showed bilateral cortical ribboning locations in the occipital and parietal lobes on the DWI sequence (arrows). (C and D) No obvious abnormal signal at the corresponding locations on fluid-attenuated inversion recovery sequence. (E) Slightly abnormal signal in the local cerebral cortex and left caudate head on T2 sequence (arrows). (F) Cortical ribboning shows abnormal hyperintensity signals in nearly all lobes and an abnormal hyperintensity signal in the caudate head and putamen was visible on DWI sequence (arrows). DWI, diffusion-weighted imaging.

mutism state, he was given tube feeding. Due to attentive nursing care and supportive treatments, the patient had few complications and died in December 2011, more than six years after the occurrence of the first symptoms.

Second case. In February 2011, a 66-year-old woman with no remarkable family and past clinical history was admitted to Qilu Hospital of Shandong University due to progressive memory decline and language disorders for four months and myoclonus of the right upper limb for one month. According to the patient's daughter, the patient's memory had been deteriorating and her language was impaired regarding names and expression of words. Upon admission, she was able to perform daily activities. Over 4 months, the symptoms then progressed so rapidly that at times, she was not able to remember her children's names. In December 2010, the patient was given a brain MRI due to memory deterioration that was associated with an abnormal signal in the localized cortex (Fig. 3). The patient was then referred to her local hospital, the Second Hospital of Shandong University, and received treatments to alleviate the symptoms, which, however, did not lead to any improvements.

One month later, the patient showed a regression of understanding and expression. The mental state of the patient 


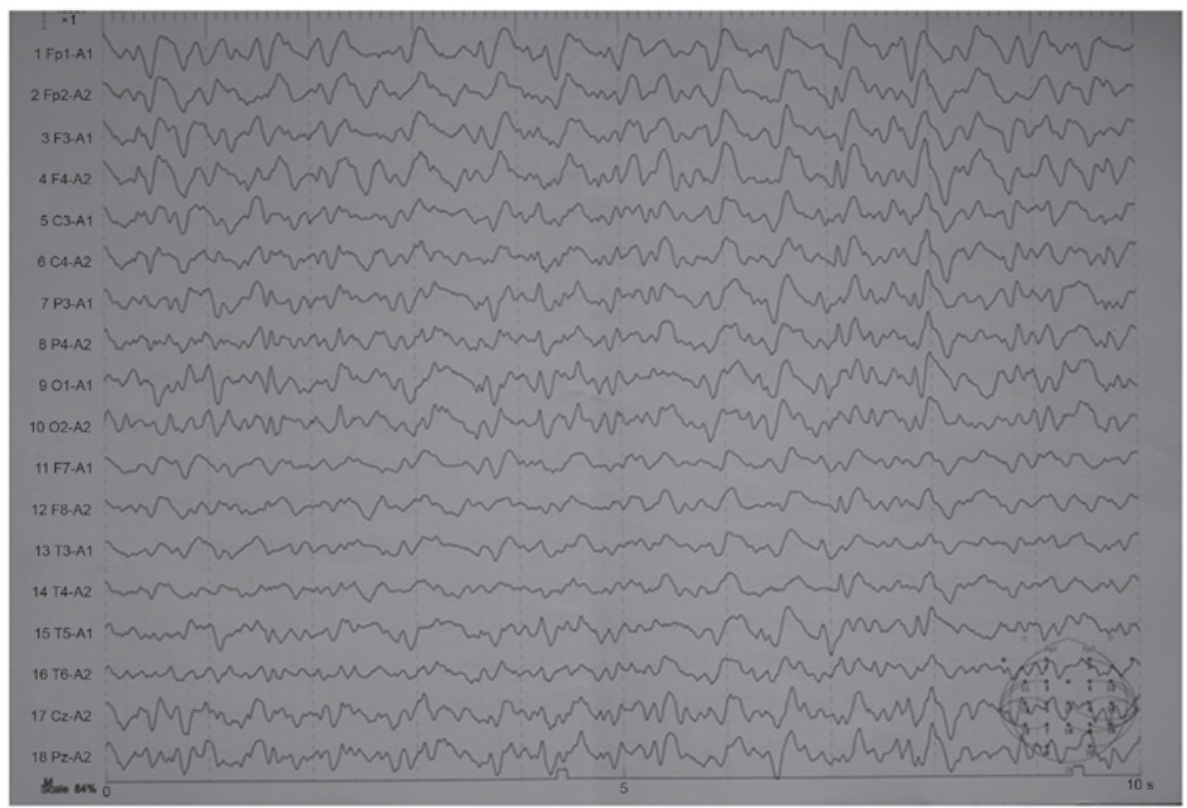

Figure 4. Electroencephalogram of the second case showing slow biphasic waves and focal triphasic periodic sharp wave complexes.

appeared dull and she did not speak spontaneously. After one month, her memory loss aggravated so quickly that she could hardly complete any simple action. Furthermore, new symptoms developed, such as hallucinations and spontaneous jerky myoclonus of the right upper limb all day. The patient was then referred to the local hospital again, but the clinical symptoms kept deteriorating, so the she was sent back to our hospital.

Psychiatric evaluation upon re-admission in February 2011 revealed that the patient was alert and uncooperative. Her speech was mostly comprised of nonsensical words. On occasion, she was able to mumble one or two separate words but was unable to form full sentences. Physical examination at this time-point revealed severe cognitive impairment, dysphasia, positive right side Babinski sign and myoclonus of the right upper limb. The patient's short- and long-term memory were severely affected, with disorientation regarding time and location. All laboratory tests were normal or negative, including routine blood, urine and stool tests, erythrosedimentation, liver and kidney function, thyroid function, antithyroid peroxidase antibodies, antithyroid-globulin antibodies, blood glucose, lipid, folic acid and vitamin B12 level and autoimmune antibody level, and screening tests for human immunodeficiency virus and venereal diseases were negative. EEG showed slow biphasic waves and PSWC (Fig. 4). The CSF was positive for 14-3-3 protein. PRNP gene analysis showed the patient was homozygous for $\mathrm{M}$ at codon 129 (129 M/M) with no mutation. Brain MRI showed bilateral cortical ribboning on DWI in the occipital and parietal lobes. The abnormalities previously identified by MRI worsened in February 2011 relative to those of December 2010 (Fig. 3). In March 2011, the scope of cortical ribboning significantly expanded as clinical symptoms aggravated (Fig. 3E and F).

With the diagnosis of probable CJD, supportive treatments were given to improve cognitive function, which, however, had no marked effects. The disease progressed rapidly and the patient quickly lapsed into an akinetic mutistic state and required feeding with assistance. Five months after the first symptoms, the patient succumbed to pneumonia.

Third case. The third patient was a 74-year-old man with hypomnesia for 2 months and hyposthenia of the right upper limb for ten days. Initially, the patient noted that his memory gradually declined but had received no treatment. However, his right upper limb appeared weak and showed heteronomous buffeting, accompanied with instability of gait ten days prior to admission.

Subsequent to admission to Qilu Hospital of Shandong University in December 2012, physical examination showed cognitive impairment, ataxia, muscle weakness and myoclonus of limbs. The laboratory tests were all normal or negative, including routine blood, urine and stool tests, erythrosedimentation, liver and kidney function, thyroid function, antithyroid peroxidase antibodies, antithyroid-globulin antibodies, blood glucose, lipid, folic acid and vitamin B12 level, autoimmune antibody levels, and screening tests for human immunodeficiency virus and venereal diseases. Brain MRI revealed bilateral cortical ribboning on DWI in the frontal, occipital, insular and parietal lobes and caudate head (Fig. 5). EEG showed classic PSWC during the patient's hospital stay (December 2012) (Fig. 6). At this time-point, CSF examination was positive for 14-3-3 protein. Gene analysis showed the patient was homozygous for the $\mathrm{M} / \mathrm{M}$ polymorphism at codon 129 of PRNP, with a T188K mutation.

The rapidly progressive cognitive decline, spontaneous myoclonus, and the typical EEG and brain MRI features all supported the diagnosis of CJD. Although treatments to improve cerebrocirculation and cerebrometabolism had been given in an attempt to delay the course of the disease or improve the symptoms, the patient's clinical symptoms deteriorated. He stayed at Qilu Hospital of Shandong University for 18 days and was then transferred to his local hospital 
A

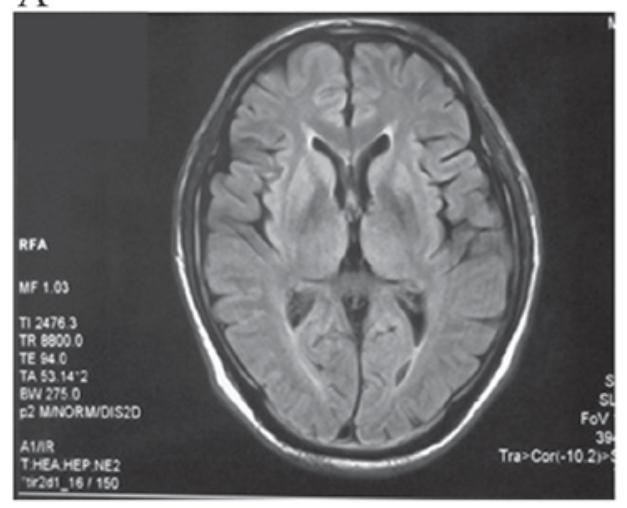

$\mathrm{B}$

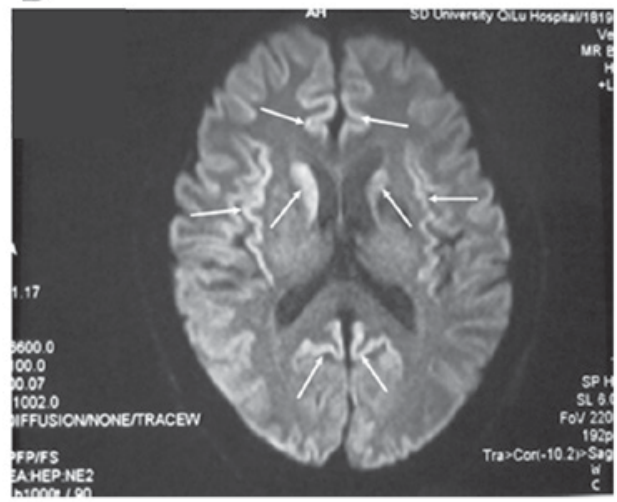

Figure 5. Brain MRI of the third case. (A) No obvious abnormal signal at the corresponding locations on fluid-attenuated inversion recovery sequence. (B) Brain MRI showed bilateral cortical ribboning of several cortical locations in the frontal, occipital and insular lobes as well as the caudate head on diffusion-weighted imaging sequence (arrows). MRI, magnetic resonance image.

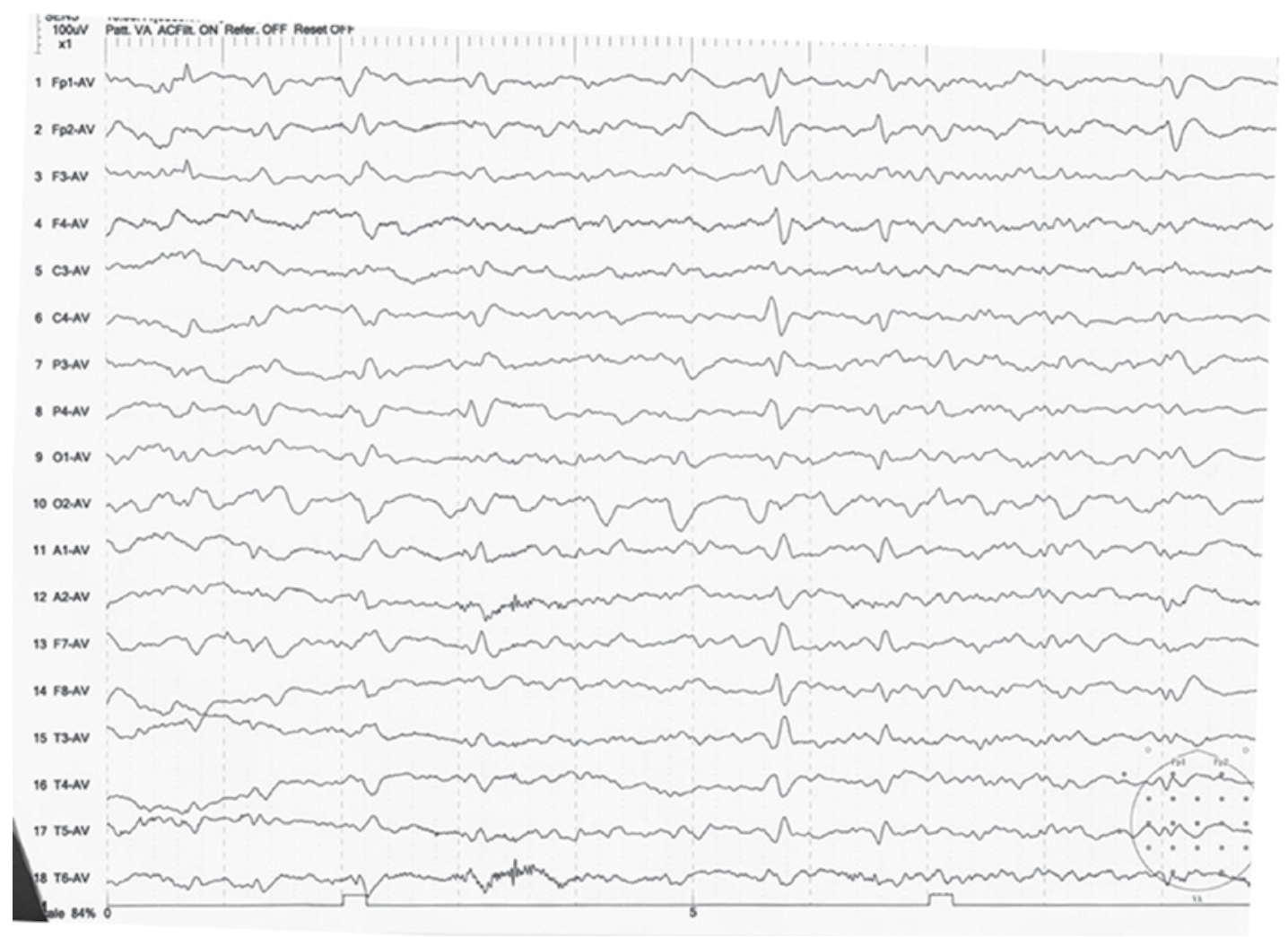

Figure 6. Electroencephalogram of the third case showing triphasic sharp wave complexes (PSWC).

(Binzhou Municipal People's Hospital). Over the subsequent days, with a rapid decline in memory, the patient developed akinetic mutism. He died in April 2013, about ten months after the occurrence of the first symptoms.

\section{Discussion}

CJD is a rare but inevitably fatal neurological disorder, which is associated with spongiform changes in the brain and an accumulation of a misshapen protein known as prion (16). CJD is characterized as a rapid deterioration in cognition, ranging from confusion over memory loss to severe dementia, accompanied by headache, anxiety, insomnia, depression, behavioral changes, agitation, impaired judgment, ataxia, myoclonus, limb weakness, as well as speech and visual impairments (17). The clinical presentation of CJD is relatively nonspecific, making it hard for it to be distinguished from numerous other diseases. The first symptoms can be subtle and are thus often overlooked; therefore, it is difficult to diagnose CJD, particularly in early stages or atypical cases. According to the WHO diagnostic criteria, the diagnosis of prion disease can be confirmed by autopsy or brain biopsy to pathologically reveal spongiosis, neuronal loss, gliosis and PRNP (15). However, due to Chinese traditions, the bodies of deceased patients are respected and kept intact, and are therefore rarely dissected or pathologically examined. 
Therefore, in combination with the transmissible nature of the disease, autopsy or brain biopsy cannot be performed due to limited medical resources in China and in India (18). Given this diagnostic dilemma, nonpathological methods are sought as a reference standard, and active surveillance and effective diagnosis of CJD are critical (19).

The present study reported on the clinical symptoms and laboratory examinations of the three CJD patients whose initial and primary symptoms were atypical. However, the three cases eventually developed CJD, followed by gradual aggravation of rapidly progressive cognitive decline, spontaneous myoclonus, ataxia and akinetic mutism with EEG, MRI and CSF all supporting the diagnosis of CJD. According to the present cases and a previous report (20), all examination methods have false positive and false negative diagnostic rates at different courses of the disease; therefore, dynamic, careful and comprehensive observation of patients with suspected CJD is warranted.

At present, EEG, biomarkers in CSF, MRI and gene analysis are in use for determining brain diseases (21). EEG showed characteristic changes in all disease stages of CJD, ranging from nonspecific findings such as diffuse slowing and frontal rhythmic delta activity in early stages to typical PSWC in the middle and late stages. PSWC occurs in 66-67\% of patients with SCJD, and the specificity can be as high as $74-86 \%(21,22)$. The three cases of the present study were subjected to serial EEG throughout the course of the disease and not all of them had typical PSWC; in the first case, PSWC was not detected, while it rapidly developed in the other two cases at different stages. According to a previous study, EEGs are normal in numerous cases of CJD at the early stage; however abnormal EEG findings may differ among different CJD subtypes (23). Abnormal EEG findings occur in patients with $\mathrm{M}$ homozygosis and $\mathrm{M} / \mathrm{V}$ heterozygosis but rarely in patients with V homozygosis at codon 129 of the PRNP (24).

The detection of CSF biomarkers such as 14-3-3 protein, tau protein, S-100 protein and neuron-specific enolase as diagnostic markers has been shown to improve the sensitivity of clinical diagnosis even in the early stages of CJD (25). Total tau protein can be used as a diagnostic test for the assessment of PRNP when the codon 129 genotype is known (26), while the marker is not CJD-specific and can also be detected in numerous other diseases. Certain studies have shown that the sensitivity of 14-3-3 protein for detecting CJD varies for different CJD genotypes: From 57\% in MV2 to $100 \%$ in MV1 and VV1 cases, with a specificity from 84 to $95 \%(27,28)$. However, the level of $14-3-3$ protein varies over time and may not be detectable at certain time-points in certain patients (29). In the present study, the 14-3-3 protein test in the CSF was $\sim 67 \%$ positive, as the first patient (M/M type) was negative. After the first detection, the patient's relatives did not consent to the dynamic recheck of 14-3-3 protein, and it was therefore not assessed thereafter. Furthermore, the test may have been performed when the first patient was an undetectable stage, so it cannot be ruled out that the 14-3-3 protein test was false negative. However, there is also a chance that the 14-3-3 protein test was false positive in the other two patients of the present study (30).

MRI is a tool that is increasingly useful in the evaluation and early detection of suspected CJD and excluding other diseases, which may possibly be treatable $(31,32)$. A retrospective study suggested that basal ganglia, subcortical signal intensity changes and cortical ribboning on DWI are the most important imaging markers (33). However, MRI scan is used only as reference, as it may vary across cases with different PRNP genes at different stages $(34,35)$. In the present cases, brain MRI showed cortical ribboning or bilateral high signals in the caudate and putamen, which were coincident with the abnormalities of typical CJD patients. Initially, the brain MRI of the first case was normal and his clinical manifestation was non-specific; therefore, until the basal ganglia hyperintensity appeared, the diagnosis of CJD was not considered. Multiple axial images of the other two patients' brain MRI scans showed bilateral cortical ribboning of several locations in the cortex on DWI at the early stage, which immediately suggested the diagnosis of CJD. With disease progression, the MRI of the first patient revealed conspicuous atrophy, while the cortical ribboning of the second case became more apparent as clinical symptoms aggravated; all of these findings indicated that the scope and extent of lesions on MRI may be associated with the severity of the disease. The reasons for different MRI presentations are not fully known but may be explained by the following: First, the examination was performed at different disease stages (36); second, MRI may have been falsely positive or negative; finally, the correlation between the subtype of CJD and imaging findings was close for each patient.

The WHO diagnostic criteria (15) for probable CJD cases specified that the disease should have been present for $<2$ years before death. In the first case, with attentive nursing and supportive treatments, the duration was extended to 6 years, which was evidently different from that of typical cases and the WHO diagnostic criteria. Tube feeding has been considered to be the most crucial factor contributing to the prolonged survival of Japanese sCJD patients (37). Therefore, the diagnosis of CJD should not be excluded solely based on longer duration, which was closely associated with nursing and supportive treatments. Appleby et al (38) reported that heterozygous cases (M/V) had a longer survival time (7.7-2.8 years) compared with that of homozygous cases (M/M and V/V; 1.7 years). PRNP gene mutations had also been analyzed in the three cases of the present study. The gene analysis showed that all of the patients were homozygous for methionine at codon 129 of the PRNP gene. A previous study indicated that the $\mathrm{T} 188 \mathrm{~K}$ mutation is likely to be a dominant genotype of CJD in Chinese patients (39). In the present study, one of the cases had the T188K mutation, while the others did not. However, the polymorphisms of PRNP at codon 129 in the first case were not consistent with those in the study by Appleby et al (38), so that the prolonged duration cannot be explained. Different from typical CJD patients, codon 129 polymorphisms of PRNP in this present case was not the key factor determining the survival time. It is possible that the further CJD subtypes may be accountable for the divergence in survival time. Due to restricting circumstances, other codons and their polymorphisms were not analyzed in the present study. In all three cases, no risk factors for CJD and no family history of the disease were found, so that the etiology of the disease was not fully known.

In conclusion, the diagnosis of CJD is often neglected and requires numerous laboratory and pathology examinations. 
Physicians should have a comprehensive understanding of CJD and consider its diagnosis if patients show physical signs associated with it. Different subtypes may have different clinical and laboratory presentations. It is important that more specific and sensitive tests and examinations are performed to increase the diagnostic rate in order to diagnose probable CJD earlier, even prior to the appearance of the characteristic clinical symptoms. This would benefit disease prevention and may allow for early treatment in the future. Further investigation is required to fully elucidate the etiology, pathogenesis, diagnostic criteria, precautionary measures and treatments for CJD.

\section{References}

1. Corić L, Vargek-Solter V, Supanc V, Miskov S, Drnasin S, Sabolek K, Bedek D and Demarin V: Sporadic Creutzfeldt-Jakob disease in a patient with episodes of nonconvulsive status epilepticus: Case report. Acta Clin Croat 51: 89-92, 2012

2. Haider E, Wali W, Raja S and Tariq M: Creutzfeldt Jakob disease. J Coll Physicians Surg Pak 23: 295-297, 2013.

3. Sikorska B,KnightR, Ironside JW and LiberskiPP: Creutzfeldt-Jakob disease. Adv Exp Med Biol 724: 76-90, 2012.

4. Gambetti P, Kong Q, Zou W, Parchi P and Chen SG: Sporadic and familial CJD: Classification and characterisation. Br Med Bull 66 : 213-239, 2003.

5. Parchi P, Giese A, Capellari S, Brown P, Schulz-Schaeffer W, Windl O, Zerr I, Budka H, Kopp N, Piccardo P, et al: Classification of sporadic Creutzfeldt-Jakob disease based on molecular and phenotypic analysis of 300 subjects. Ann Neurol 46: 224-233, 1999.

6. Ladogana A, Puopolo M, Croes EA, Budka H, Jarius C, Collins S, Klug GM, Sutcliffe T, Giulivi A, Alperovitch A, et al: Mortality from Creutzfeldt-Jakob disease and related disorders in Europe, Australia and Canada. Neurology 64: 1586-1591, 2005.

7. Kovács GG, Puopolo M, Ladogana A, Pocchiari M, Budka H, van Duijn C, Collins SJ, Boyd A, Giulivi A, Coulthart M, et al: Genetic prion disease: The EUROCJD experience. Hum Genet 118: 166-174, 2005.

8. Bratosiewicz-Wasik J, Smolen-Dzirba J, Rozemuller AJ, Jansen C, Spliet W, Jansen GH, Wassik TJ and Liberski PP: Association between the PRNP 1368 polymorphism and the occurrence of sporadic Creutzfeldt-Jakob disease. Prion 6: 413-416, 2012.

9. Krasnianski A, von Ahsen N, Heinemann U, Meissner B, Schulz-Schaeffer WJ, Kretzschmar HA, Armstrong VW and Zerr I: Increased frequency of positive family history of dementia in sporadic CJD. Neurobiol Aging 30: 615-621, 2009.

10. Brown P and Farrell M: A practical approach to avoiding iatrogenic Creutzfeldt-Jakob disease (CJD) from invasive instruments. Infect Control Hosp Epidemiol 36: 844-848, 2015.

11. Llewelyn CA, Hewitt PE, Knight RS, Amar K, Cousens S, Mackenzie J and Will RG: Possible transmission of variant Creutzfeldt-Jakob disease by blood transfusion. Lancet 363: 417-421, 2004.

12. Ward HJ, Everington D, Cousens SN, Smith-Bathgate B, Leitch M, Cooper S, Heath C, Knight RS, Smith PG and Will RG: Risk factors for variant Creutzfeldt-Jakob disease: A case-control study. Ann Neurol 59: 111-120, 2006.

13. Ward HJ, MacKenzie JM, Llewelyn CA, Knight RS, Hewitt PE, Connor N, Molesworth A and Will RG: Variant Creutzfeldt-Jakob disease and exposure to fractionated plasma products. Vox Sang 97: 207-210, 2009.

14. Ragno M, Scarcella MG, Cacchiò G, Capellari S, Di Marzio F, Parchi P and Trojano L: Striatal [123I] FP-CIT SPECT demonstrates dopaminergic deficit in a sporadic case of Creutzfeldt-Jakob disease. Acta Neurol Scand 119: 131-134, 2009.

15. World Health Organization: Global surveillance, diagnosis and therapy of human transmissible spongiform encephalopathies: Report of a WHO consultation. Geneva, 1998.

16. Cyngiser TA: Creutzfeldt-Jakob disease: A disease overview. Am J Electroneurodiagnostic Technol 48: 199-208, 2008.

17. Iwasaki Y, Mimuro M, Yoshida M, Sobue G and Hashizume Y: Clinical diagnosis of Creutzfeldt-Jakob disease: Accuracy based on analysis of autopsy-confirmed cases. J Neurol Sci 277: 119-123, 2009.

18. Gadgil NM, Chaudhari CS, Gohil SD and Kalgutkar AD: Creutzfeldt-Jacob disease: An autopsy case report in tertiary care hospital. Indian J Pathol Microbiol 55: 97-99, 2012.
19. Lee J, Hyeon JW, Kim SY, Hwang KJ, Ju YR and Ryou C: Review: Laboratory diagnosis and surveillance of Creutzfeldt-Jakob disease. J Med Virol 87: 175-186, 2015

20. Zhao X, Yu Y, Zhao Z and Xu J: Comparison between sporadic and misdiagnosed sporadic Creutzfeldt-Jakob disease: A report of two cases. Cell Biochem Biophys 72: 311-315, 2015.

21. Wang PS, Wu YT, Hung CI, Kwan SY, Teng S and Soong BW: Early detection of periodic sharp wave complexes on EEG by independent component analysis in patients with Creutzfeldt-Jakob disease. J Clin Neurophysiol 25: 25-31, 2008.

22. Wieser HG, Schindler K and Zumsteg D: EEG in Creutzfeldt- Jakob disease. Clin Neurophysiol 117: 935-951, 2006.

23. Hashimoto T, Iwahashi T, Ishii W, Yamamoto K and Ikeda S: EEG-EMG polygraphic study of dystonia and myoclonus in a case of Creutzfeldt-Jakob disease. Epilepsy Behav Case Rep 4: 30-32, 2015.

24. Steinhoff BJ, Zerr I, Glatting M, Schulz-Schaeffer W, Poser S and Kretzschmar HA: Diagnostic value of periodic complexes in Creutzfeldt-Jakob disease. Ann Neurol 56: 702-708, 2004.

25. Pennington C, Chohan G, Mackenzie J, Andrews M, Will R, Knight R and Green A: The role of cerebrospinal fluid proteins as early diagnostic markers for sporadic Creutzfeldt-Jakob disease. Neurosci Lett 455: 56-59, 2009.

26. Karch A, Hermann P, Ponto C, Schmitz M, Arora A, Zafar S, Llorens F, Müller-Heine A and Zerr I: Cerebrospinal fluid tau levels are a marker for molecular subtype in sporadic Creutzfeldt-Jakob disease. Neurobiol Aging 36: 1964-1968, 2015.

27. Muayqil T, Gronseth G and Camicioli R: Evidence-based guideline: Diagnostic accuracy of CSF 14-3-3 protein in sporadic Creutzfeldt-Jakob disease: Report of the guideline development subcommittee of the American Academy of Neurology. Neurology 79: 1499-1506, 2012.

28. Sanchez-Juan P, Green A, Ladogana A, Cuadrado-Corrales N, Sáanchez-Valle R, Mitrováa E, Stoeck K, Sklaviadis T, Kulczycki J, Hess K, et al: CSF tests in the differential diagnosis of Creutzfeldt-Jakob disease. Neurology 67: 637-643, 2006.

29. Cramm M, Schmitz M, Karch A, Zafar S, Varges D, Mitrova E, Schroeder B, Raeber A, Kuhn F and Zerr I: Characteristic CSF prion seeding efficiency in humans with prion diseases. Mol Neurobiol 51: 396-405, 2015.

30. Satoh K, Shirabe S, Eguchi H, Tsujino A, Eguchi K, Satoh A, Tsujihata M, Niwa M, Katamine S, Kurihara S and Matsuo H: 14-3-3 protein, total tau and phosphorylated tau in cerebrospinal fluid of patients with Creutzfeldt-Jakob disease and neurodegenerative disease in Japan. Cell Mol Neurobiol 26: 45-52, 2006.

31. Forner SA, Takada LT, Bettcher BM, Lobach IV, Tartaglia MC, Torres-Chae C, Haman A, Thai J, Vitali P, Neuhaus J, et al: Comparing CSF biomarkers and brain MRI in the diagnosis of sporadic Creutzfeldt-Jakob disease. Neurol Clin Pract 5: 116-125, 2015.

32. Paterson RW, Torres-Chae CC, Kuo AL, Ando T, Nguyen EA Wong K, DeArmond SJ, Haman A, Garcia P, Johnson DY, et al: Differential diagnosis of jakob-creutzfeldt disease. Arch Neurol 69: 1578-1582, 2012.

33. Tabrizi $\mathrm{N}$ and Abedini M: Unilateral cortical hyperintensity in diffusion-weighted MRI; New criteria for early sporadic Creutzfeldt-Jakob disease. Iran J Neurol 14: 108-109, 2015.

34. Vitali P, Maccagnano E, Caverzasi E, Henry RG, Haman A, Torres-Chae C, Johnson DY, Miller BL and Geschwind MD: Diffusion-weighted MRI hyperintensity patterns differentiate CJD from other rapid dementias. Neurology 76: 1711-1719, 2011.

35. Furukawa F, Ishibashi S, Sanjo N, Yamashita $H$ and Mizusawa $H$ : Serial magnetic resonance imaging changes in sporadic Creutzfeldt-Jakob disease with valine homozygosity at codon 129 of the prion protein gene. JAMA Neurol 71: 1186-1187, 2014.

36. Morgan C, Gupta M, El-Feky W, Shamim S and Opatowsky M: Creutzfeldt-Jakob disease: Case discussion and imaging review. Proc (Bayl Univ Med Cent) 22: 69-71, 2009.

37. Iwasaki Y, Akagi A, Mimuro M, Kitamoto T and Yoshida M: Factors influencing the survival period in Japanese patients with sporadic Creutzfeldt-Jakob disease. J Neurol Sci 357: 63-68, 2015.

38. Appleby BS, Appleby KK, Crain BJ, Onyike CU, Wallin MT and Rabins PV: Characteristics of established and proposed sporadic Creutzfeldt-Jakob disease variants. Arch Neurol 66: 208-215, 2009.

39. Chen C, Shi Q, Zhou W, Zhang XC, Dong JH, Hu XQ, Song XN, Liu AF, Tian C, Wang JC, et al: Clinical and familial characteristics of eight Chinese patients with T188K genetic Creutzfeldt-Jakob disease. Infect Genet Evol 14: 120-124, 2013. 